\title{
EVOLVING TRENDS AND FUTURE PROSPECTS OF ADR MONITORING AND REPORTING: A LITERATURE REVIEW
}

\author{
ANEELA AMIN, MADEEHA MALIK*, AZHAR HUSSAIN \\ Department of Pharmacy, Hamdard Institute of Pharmaceutical Sciences, Hamdard University, Islamabad, \\ Pakistan. Email: madeehamalik15@gmail.com
}

Received: 10 May 2016, Revised and Accepted: 21 May 2016

\section{ABSTRACT}

Objective: Owing to the importance of safe use of medicines, adverse drug reaction (ADR) monitoring has become a fundamental component to be performed along with other health-care services. Pharmacist being drug experts are in good position to provide professional assistance for ADR management. The aim of this study is to summarize research findings from developed and developing countries as well as from Pakistan regarding evolving trends and future prospects of ADR monitoring and reporting by pharmacists. Methods: A total of 49 studies were reviewed regarding trends of ADR monitoring using different search engines including google scholar, pubmed and science direct. Results: The review highlighted that there is need to identify the barriers and gaps to further enhance the effectiveness of current ADR monitoring practices. Conclusion: Strong legislation is required in Pakistan to develop and implement an effective ADR monitoring program to reinforce the conception of effective pharmacovigilance system in Pakistan.

Keywords: Adverse drug reactions, Reporting, Pharmacist, Pharmacovigilance, Pakistan.

(C) 2016 The Authors. Published by Innovare Academic Sciences Pvt Ltd. This is an open access article under the CC BY license (http://creativecommons. org/licenses/by/4. 0/) DOI: http://dx.doi.org/10.22159/ajpcr.2016.v9i5.12725

\section{INTRODUCTION}

Adverse drug reactions (ADRs) are posing a major challenge to the health-care system as they compromise on the safety of drug therapy. ADRs are not only the cause of mortality and morbidity but are also contributing toward increased cost of health-care services [1]. Approximately, 5000 deaths and 6.5\% hospital admissions in England were reported due to ADRs [2]. Nearly $2-4 \%$ of the hospital admissions in Australia were result of ADRs effecting both young and elderly, out of which most of them could be preventable $[3,4]$.

ADRs cannot be detected during pre-clinical trials; safety of drugs is established by monitoring its use under real-time conditions. International drug monitoring program was initiated in 1970, in which National Pharmacovigilance centers of different countries coordinate with WHO collaborating Centre for International Drug Monitoring in Uppsala, Sweden. This center maintains international database of ADRs after reviewing reports from national centers and promote rapid identification of signals by facilitating communication among different countries. An increasing number of developing countries are also participating in this program along with the current 78 member countries [5].

By accepting the responsibility of preventing drug-related mortality and morbidity, pharmacy profession has created an opportunity to take this profession to the next level to cope up with advanced concept of public healthcare, i.e., "If pharmaceutical care can prevent treatment failure or other drug-related morbidity or mortality, it is much more valuable than the services incident to selling a drug product" [6].

Meta-analysis of literature shows that pharmacists are better in the detection of ADRs as an inpatient chart reviewer as compared to charts reviewed by other health-care professionals. Pharmacist's knowledge of drugs and clinical therapeutics as well as drug safety, place them in a better position to identify ADRs and monitor drug surveillance programs [7]. Pharmacist-led monitoring system at the hospital is effective in detecting ADRs of newly marketed drugs. However, only computer programs not designed as patient focused is not able to identify patients taking newly marketed drugs which should be under strict surveillance [8]. The pharmacist has helped to improve outcomes including reduction in ADRs and medication errors by improving medication adherence through counseling and telephone follow-up which has resulted in identification of preventable adverse drug events. Similar findings were highlighted in a study which reviewed the role of pharmacists in intensive care units [9-11].

\section{METHODS}

PubMed, Google scholar, and ScienceDirect were the databases used to search for articles published from January 1988 to December 2015. Terms used to search each database were ADR monitoring, pharmacists, ADR reporting system, and role of pharmacist in ADR monitoring. Fulltext papers as well as abstracts were retrieved and included in review. A total of 49 studies were retrieved from databases related to ADR monitoring and role of pharmacist in it. The studies were categorized on the basis of their country of publishing into developed countries, developing countries and Pakistan. 23 studies from developed countries, 22 from developing countries, and 4 studies from Pakistan were included in this review (Table 1). Quantitative cross-sectional surveys, as well as qualitative studies, were also included.

\section{RESULTS AND DISCUSSION}

\section{ADR monitoring trends in developed countries}

Many developed countries have their own ADR monitoring systems. In UK, Medicines and Healthcare Products Regulatory Agency regulates the ADR monitoring through yellow card scheme. The Netherlands pharmacovigilance Centre is functional in Netherland, Sweden, USA, New Zealand, Singapore, Australia, and Canada have reporting systems that coordinate with their national pharmacovigilance centers [12]

ADR reporting is strongly influenced by knowledge and attitudes of pharmacists. However, their attitudes and practice might be influenced by setting and their working experience [13]. Pharmacists in Texas showed positive intentions toward reporting an ADR to Food and Drug Administration (FDA) and most of them were of the view that ADR reporting will improve patient safety [14]. Another study from the USA reported that pharmacy students were well aware of the ADR reporting programs but had little knowledge regarding reporting procedures and correct use of forms for reporting ADRs used by the pharmacovigilance programs [15]. However, pharmacy students in the USA had positive intentions toward reporting ADR to FDA [16]. 
Table 1: Details of country and number of included papers

\begin{tabular}{|c|c|c|}
\hline Regions & $\begin{array}{l}\text { Number } \\
\text { of studies }\end{array}$ & Countries \\
\hline $\begin{array}{l}\text { Developed } \\
\text { countries }\end{array}$ & 23 & $\begin{array}{l}\text { USA, Australia, UK, Japan, Germany, } \\
\text { Belgium, Switzerland, Sweden, } \\
\text { Canada, Denmark, Greece, Spain, } \\
\text { Italy, Finland, Ireland, Netherlands }\end{array}$ \\
\hline $\begin{array}{l}\text { Developing } \\
\text { countries }\end{array}$ & 22 & $\begin{array}{l}\text { Turkey, China, South Africa, Ghana, } \\
\text { Malaysia, India, Taiwan, Iran, Qatar, } \\
\text { Eritrea, Jordan }\end{array}$ \\
\hline Pakistan & 4 & - \\
\hline Total & & 49 \\
\hline
\end{tabular}

Both community and hospital pharmacists can participate in ADR reporting, hospital pharmacists being in direct contact of ADRs play a key role in ADR monitoring. However, community pharmacists can also be the key participants in ADR monitoring by extending their traditional practices of dispensing and procurement [17]. Community pharmacists have been reported to show a positive attitude toward ADR reporting [17]. Although they were well aware of their role regarding ADR monitoring, reporting of ADRs by community pharmacists was reported quite low [18]. Similar findings of under-reporting of ADRs by community pharmacists were reported in the UK [19]. On the other hand, community pharmacists in Netherland were actively participating in ADR reporting and considered it as a legal implication toward their profession [20]. Community pharmacists from UAE and Hong Kong showed positive attitude toward ADR reporting though they had poor knowledge and awareness regarding ADR reporting system and pharmacovigilance activities, which probably might be the cause of under-reporting of ADRs [21,22].

Hospital led monitoring systems to report and identify ADRs can also be used along with other spontaneous reporting systems for better monitoring of ADRs as it will provide better understanding of events related to ADR [8]. A study from the UK reported, that although hospital pharmacists were well aware of ADR reporting schemes, were inconsistent in reporting [23]. Owing to the global importance of drug safety pharmacists have to play active role in ADR monitoring. In Japan, pharmacovigilance plan has been included under risk management plan initiated but still spontaneous reporting of ADRs by pharmacists is poor [12]. National ADR monitoring center (center for adverse reactions monitoring) is working in collaboration with WHO International Drug Monitoring Program in New Zealand. ADR reports submitted by hospital pharmacists are less as compared to physicians, however, in contrary to this ADR reporting rate by hospital pharmacists is higher as compared to that by physicians in USA and Canada [24,25]. ADR reports submitted by the pharmacist were found to be fairly complemented to those submitted by the physicians [25].

Spontaneous reporting has been used as an important tool for reporting ADRs. However, alone it may not be proved sufficient to determine the underlying causes of ADRs for their prevention [4]. ADR reporting programs involving healthcare team including (doctors, nurses, and pharmacists) had been proved more fruitful in the management of ADRs as compared to those involving of just physicians [7]. Adequate knowledge and training regarding ADRs can empower pharmacists to identify, assess and report ADR [24]. Literature reviewed recommend the need to further probe the role of pharmacists in understanding the nature of ADRs and development of efficient ADR reporting system with specific outcomes for computing the success or failure of the system. Further studies should be conducted to identify the gaps in current systems to improve their efficiency. Beside this motivational measures must be identified for engaging pharmacists and other healthcare professionals in ADR reporting.

ADR monitoring trends in developing countries

Many developing countries including India, Jordan, Brazil, Malaysia,
South Africa, and Ukraine have reporting systems engaged in ADR monitoring which collect data and send it to WHO ADR monitoring center at Uppsala, Sweden [25]. China ADR monitoring system collects data from national, provincial, municipal centers and generates drug safety reports after analyzing data [26]. The concept of ADR monitoring is still not matured in Nepal, strong need to develop monitoring systems at hospitals level is required to initiate the idea of pharmacovigilance [24]. A cross-sectional study in Nepal showed poor knowledge of ADR and pharmacovigilance, although pharmacists had a positive attitude toward their role in ADR monitoring. Poor reporting of ADRs was due to being unfamiliar with the pharmacovigilance system [27].

Although pharmacists can play an effective role in ADR monitoring as compared to other healthcare professionals, due to the absence of ADR reporting systems in hospitals reporting of ADR was found low [28]. In another study conducted in Malaysia pharmacy, students showed better understanding and knowledge of pharmacovigilance related activities as compared to medical students [29]. A good number of hospital pharmacists in China were well aware of the term ADR and consider their reporting as professional obligation but few of them ever reported them [30]. Hospital pharmacists in Malaysia possessed a good knowledge of ADRs, however, to improve reporting rate, more training and educational programs were required [25]. India has re-launched its pharmacovigilance program in 2010. Several studies conducted in India reported that pharmacists had inadequate knowledge regarding $\mathrm{ADR}$ reporting and poor participation and attitude regarding their role in drug safety issues [31-33].

Studies from Riyadh, Alahsa, and Makkah reported that community pharmacists were unaware of ADR reporting system and possessed low knowledge regarding ADR and pharmacovigilance term; however, they showed a positive attitude toward getting trained and their active participation in ADR reporting [34-37]. On the other hand, community pharmacists in Malaysia possessed good knowledge of ADR and pharmacovigilance. However, the low practice was found due to their unawareness regarding pharmacovigilance system [38,39]. Community pharmacists in India also possessed poor knowledge and practices toward ADR reporting and most of them are involved in traditional practices of dispensing at community pharmacies $[39,40]$. The majority of the community pharmacists in Nigeria and Ethopia showed a positive attitude toward ADR reporting and pharmacovigilance and were well aware of their role in ADR reporting and pharmacovigilance, however, ADR reporting rate was poor due to lack of awareness about pharmacovigilance and motivation to report ADRs [41]. Similarly, study conducted in Kadikoy district of Istanbul showed that only few pharmacists reported ADRs to national pharmacovigilance center [42].

Studies from Iran reported that although pharmacists were well aware of their professional obligations to report ADRs but pharmacists still underestimate the importance of reporting ADR which lead to underreporting of ADRs $[43,44]$. Similarly, despite the establishment of ADR reporting system in Jordan, pharmacists had little knowledge regarding ADR due to which reporting rate was very low, but they had positive attitude toward ADR reporting and pharmacovigilance [45]. The majority of studies from developing world highlighted poor knowledge and awareness of pharmacists regarding ADR reporting system. Urgent need of research is required to identify barriers for poor participation of pharmacists in ADR reporting. Interventional studies must be conducted to identify best possible means to educate and train pharmacists to enhance their abilities either during studies or during their professional lives.

\section{ADR monitoring trends in Pakistan}

Pharmacovigilance concept is in its initial stages in Pakistan. An ADR reporting form is available at Drug Regulatory Authority of Pakistan website [46]. More than 500 national pharmaceutical industries and more than 20 multinational pharmaceutical companies are working in Pakistan meeting $70 \%$ of the country's medicinal needs but no active pharmaceutical participation toward pharmacovigilance has been 
reported [47]. A cross-sectional study from Lahore shows that $80 \%$ of the hospitals have no proper ADR monitoring system, only one hospital is having online reporting system; four hospitals are targeting specific ADRs while few of the hospitals have ADR monitoring policy [48] A study from Karachi reported that senior pharmacy students are motivated to practice pharmacovigilance activities during clerkship as well as during their professional career [49]. Pharmacists are involved in traditional dispensing and material management practices.

Although laws do exist in Pakistan regarding ADR monitoring, there is no national database at present which can collaborate with WHO drug monitoring program to improve treatment outcomes [49,50]. Pakistan can adopt WHO guidelines of patient safety to broaden the concept of pharmacovigilance. Pharmacist's role in clinical services still needs to be recognized. This ignorance has limit the initiation of pharmaceutical care concept in health-care system of Pakistan [51,52]. ADR reporting culture should be promoted, and there should be educational training programs in hospitals for capacity building of healthcare professionals. The general public should be made aware of benefits of ADR monitoring [50]. Thus, there is strong need to recognize global standards of promoting safe use of drugs and to implement a pharmacovigilance system for best patient care in Pakistan [50].

\section{CONCLUSION}

The review concluded that there is need to identify the barriers and gaps to further enhance the effectiveness of current ADR monitoring practices. Role of the pharmacist has been evolved from traditional practices of dispensing and procurement toward patient care management in the developed countries. Community pharmacists along with hospital pharmacists are also involved in ADR monitoring; however, this development must be replicated in developing countries to boost the professional capabilities of the pharmacists and to promote safe use of medicines. Strong legislation is required in Pakistan to develop and implement an effective ADR monitoring program in order to reinforce the conception of effective pharmacovigilance system in Pakistan.

\section{REFERENCES}

1. Davies EC, Green CF, Taylor S, Williamson PR, Mottram DR, Pirmohamed M. Adverse drug reactions in hospital in-patients: A prospective analysis of 3695 patient-episodes. PLoS One 2009;4(2):e4439.

2. Pirmohamed M, James S, Meakin S, Green C, Scott AK, Walley TJ, et al. Adverse drug reactions as cause of admission to hospital: Prospective analysis of 18820 patients. BMJ 2004 3;329(7456):15-9.

3. Runciman WB, Roughead EE, Semple SJ, Adams RJ. Adverse drug events and medication errors in Australia. Int $\mathrm{J}$ Qual Health Care 2003;15 Suppl 1:i49-59.

4. Beijer HJ, de Blaey CJ. Hospitalisations caused by adverse drug reactions (ADR): A meta-analysis of observational studies. Pharm World Sci 2002;24(2):46-54.

5. WHO. The Safety of Medicines in Public Health Programmes: Pharmacovigilance, an Essential Tool. Geneva: WHO; 2006.

6. Hepler CD, Strand LM. Opportunities and responsibilities in pharmaceutical care. Am J Hosp Pharm 1990;47(3):533-43.

7. Phansalkar S, Hoffman JM, Nebeker JR, Hurdle JF. Pharmacists versus nonpharmacists in adverse drug event detection: A meta-analysis and systematic review. Am J Health Syst Pharm 2007;64(8):842-9.

8. Emerson A, Martin RM, Tomlin M, Mann RD. Prospective cohort study of adverse events monitored by hospital pharmacists. Hospital Adverse Event Monitoring Study (HAEMS) Group. Pharmacoepidemiol Drug Saf 2001;10(2):95-103.

9. Kaboli PJ, Hoth AB, McClimon BJ, Schnipper JL. Clinical pharmacists and inpatient medical care: A systematic review. Arch Intern Med 2006;166(9):955-64.

10. Schnipper JL, Kirwin JL, Cotugno MC, Wahlstrom SA, Brown BA, Tarvin E, et al. Role of pharmacist counseling in preventing adverse drug events after hospitalization. Arch Intern Med 2006;166(5):565-71.

11. Kane SL, Weber RJ, Dasta JF. The impact of critical care pharmacists on enhancing patient outcomes. Intensive Care Med 2003;29(5):691-8.

12. Rabbur RS, Emmerton L. An introduction to adverse drug reaction reporting systems in different countries. Int J Pharm Pract 2005;13(1):91-100

13. Herdeiro MT, Figueiras A, Polónia J, Gestal-Otero JJ. Influence of pharmacists' attitudes on adverse drug reaction reporting: A casecontrol study in Portugal. Drug Saf 2006;29(4):331-40.

14. Gavaza P, Brown CM, Lawson KA, Rascati KL, Wilson JP, Steinhardt M. Influence of attitudes on pharmacists' intention to report serious adverse drug events to the Food and Drug Administration. Br J Clin Pharmacol 2011;72(1):143-52.

15. Ting KN, Stratton-Powell DM, Anderson C. Community pharmacists' views on adverse drug reactions reporting in Malaysia: A pilot study. Pharm World Sci 2010;32:339-42.

16. Gavaza P, Bui B. Pharmacy students' attitudes toward reporting serious adverse drug events. Am J Pharm Educ 2012;76(10):194.

17. Generali JA, Danish MA, Rosenbaum SE. Knowledge of and attitudes about adverse drug reaction reporting among Rhode Island pharmacists. Ann Pharm 1995;29(4):365-9.

18. Green CF, Raval D, Proudlove C, Randall C. Community pharmacists' attitudes to adverse drug reaction reporting. Int J Pharm Pract 1999;7(2):92-9.

19. Ashcroft DM, Morecroft C, Parker D, Noyce PR. Likelihood of reporting adverse events in community pharmacy: An experimental study. Qual Saf Health Care 2006;15(1):48-52.

20. Van Groothest AM, Berg LT. Attitudes of community pharmacists in the Netherlands towards adverse drug reaction reporting. Int J Pharm Pract 2002; 10:267-72.

21. Lee KK, Chan TY, Raymond K, Critchley JA. Pharmacists' attitudes toward adverse drug reaction reporting in Hong Kong. Ann Pharmacother 1994;28:1400-3.

22. Qassim S, Metwaly Z, Shamsain M, Al Hariri Y. Reporting Adverse Drug Reactions: Evaluation of knowledge, attitude and practice among community pharmacists in UAE. Age 2014;22(30):31-40.

23. Green CF, Mottram DR, Rowe PH, Pirmohamed M. Attitudes and knowledge of hospital pharmacists to adverse drug reaction reporting. Br J Clin Pharmacol 2001;51:81-6.

24. Palaian S, Mishra P, Shankar PR, Dubey AK, Bista D, Almeida R. Safety monitoring of drugs - Where do we stand? Kathmandu Univ Med J (KUMJ) 2006;4:119-27.

25. Yadav S. Status of adverse drug reaction monitoring and pharmacovigilance in selected countries. Indian $\mathrm{J}$ Pharmacol 2008;40 Suppl 1:S4-9.

26. Zhang L, Wong LY, He Y, Wong IC. Pharmacovigilance in China: Current situation, successes and challenges. Drug Saf 2014;37:765-70.

27. Palaian S, Ibrahim MI, Mishra P. Health professionals' knowledge, attitude and practices towards pharmacovigilance in Nepal. Pharm Pract (Granada) 2011;9:228-35.

28. Abdel-Latif MM, Abdel-Wahab BA. Knowledge and awareness of adverse drug reactions and pharmacovigilance practices among healthcare professionals in Al-Madinah Al-Munawwarah, Kingdom of Saudi Arabia. Saudi Pharm J 2015;23(2):154-61.

29. Sivadasan S, Yuong YN, Woan CN, Siew CA, Nazeri AA Ravichandran $\mathrm{V}$, et al. Knowledge and perception towards pharmacovigilance and adverse drug reaction reporting among medicine and pharmacy students. World J Pharm PharmSci 2014;3(3):1652-76.

30. $\mathrm{Su} \mathrm{C}, \mathrm{Ji} \mathrm{H}, \mathrm{Su}$ Y. Hospital pharmacists' knowledge and opinions regarding adverse drug reaction reporting in Northern China. Pharm Drug Saf 2010;19:217-22

31. Upadhyaya HB, Vora MB, Nagar JG, Patel PB. Knowledge, attitude and practices toward pharmacovigilance and adverse drug reactions in postgraduate students of tertiary care Hospital in Gujarat. J Adv Pharm Technol Res 2015;6(1):29.

32. Amrita P, Roomi M. Scenario of pharmacovigilance and ADR reporting among pharmacists in Delhi. Indian J Pharm Pract 2011;4(4):29-38.

33. Ahmad A, Patel I, Balkrishnan R, Mohanta GP, Manna PK. An evaluation of knowledge, attitude and practice of Indian pharmacists towards adverse drug reaction reporting: A pilot study. Perspect Clin Res 2013;4:204-10.

34. Khan TM. Community pharmacists' knowledge and perceptions about adverse drug reactions and barriers towards their reporting in Eastern region, Alahsa, Saudi Arabia. Ther Adv Drug Saf 2013;4(2):45-51.

35. Bawazir SA. Attitude of community pharmacists in Saudi Arabia towards adverse drug reaction reporting. Saudi Pharm J 2006;14(1):75-83.

36. Mahmoud MA, Alswaida Y, Alshammari T, Khan TM, Alrasheedy A, Hassali MA, et al. Community pharmacists' knowledge, behaviors and experiences about adverse drug reaction reporting in Saudi Arabia. Saudi Pharm J 2014;22(5):411-8.

37. Al-Hazmi NN, Naylor I. A study of community pharmacists' awareness 
and contributions to adverse drug reactions (ADRs) reporting systems in the Makkah, Kingdom of Saudi Arabia (KSA). J Clin Trials 2013;3127. Doi:10.4172/2167-0870.1000127.

38. Elkalmi RM, Hassali MA, Ibrahim MI, Jamshed SQ, Al-Lela OQ. Community pharmacists' attitudes, perceptions, and barriers toward adverse drug reaction reporting in Malaysia: A quantitative insight. J Patient Saf 2014;10(2):81-7.

39. Swathy G, Dhivya PS, Waseem MD, Susmitha M, Narayana RR, Prasad B. An assessment of community pharmacist attitude towards professional practice and knowledge of adr in South India. IJPT 2013; 4(4):236-41.

40. Prakasam A, Nidamanuri A, Kumar S. Knowledge, perception and practice of pharmacovigilance among community pharmacists in South India. Pharm Pract (Granada) 2012;10:222-6.

41. Hailu W, Bhagavathula AS, Admassie E, Patel I, Khan TM. Knowledge, attitude and practices towards adverse drug reaction reporting in Gondar, Ethiopia. J Pharm Health Serv Res 2014;6(2):111. Doi:10.1111/ jphs. 12065.

42. Toklu HZ, Uysal MK. The knowledge and attitude of the Turkish community pharmacists toward pharmacovigilance in the Kadikoy district of Istanbul. Pharm World Sci 2008;30(5):556-62.

43. Vessal G, Mardani Z, Mollai M. Knowledge, attitudes, and perceptions of pharmacists to adverse drug reaction reporting in Iran. Pharm World Sci 2009;31:183-7.

44. Afifi S, Maharloui N, Peymani P, Namazi S, Gharaei AG, Jahani P, et al.
Adverse drug reactions reporting: Pharmacists' knowledge, attitude and practice in Shiraz, Iran. Int J Risk Saf Med 2014;26:139-45.

45. Suyagh M, Farah D, Farha RA. Pharmacist's knowledge, practice and attitudes toward pharmacovigilance and adverse drug reactions reporting process. Saudi Pharm J 2014;3:147-153.

46. Pakistan DR. 2012-13 10, May, 2015. Available from: $\quad$ http://www.dra.gov.pk/gop/index php?q=aHR0cDovLzE5Mi4xNjguNzAuMTM2L2RyYXAv.

47. Association PP. Pakistan Pharmaceutical Industry. 2008 10, May, 2015. Available from: http://www.ppma.org.pk/PPMAIndustry.aspx.

48. Mustafa G, Rasheed S, Khan MT. Adverse drug reaction reporting system at different hospitals of lahore - An evaluation and patient outcome analysis. J App Pharm.2013; 4(1): 713-719.

49. Shakeel S, Iffat W, Anjum F, Bushra R, Ibrahim S, Shafiq S. Emerging need of pharmacovigilance: Perspectives of future pharmacist in Pakistan. Int J 2014;5(2):966-9.

50. Mahmood KT, Tahir FA, Haq IU. Pharmacovigilance - A need for best patient care in Pakistan. A review. J Pharm Sci Res 2011;3(11):1566-84.

51. Azhar S, Hassali MA, Ibrahim MM. Perceptions of hospital pharmacist's role in Pakistan's healthcare system: A cross-sectional survey. Trop J Pharm Res 2011;10(1):2.

52. Hussain A, Ibrahim MI. Medication counselling and dispensing practices at community pharmacies: A comparative cross sectional study from Pakistan. Int J Clin Pharm 2011;33(5):859-67. 